\title{
SOBRE TRADUCCIONES FRACASADAS
}

No es raro encontrar textos literarios alemanes en los que el autor sitúa la acción en un lugar determinado usando una selección de denominaciones típicas (incluso los topónimos) de una región para dar más autenticidad al texto. El autor puede también reproducir el lenguaje oral, sirviéndose de formas lingüísticas marcadas como regiolectales desde el punto de vista normativo.

Puedo ilustrar este aspecto con una novela del autor austríaco Peter Handke, publicada en 1983: Der Chinese des Schmerzes (Frankfurt Main: Suhrkamp). La traducción española fue publicada en 1988 bajo el título El chino del dolor (Madrid: Alfaguara. Traductora Margarita Medina).

Es de suponer que la editorial española haya buscado para la traducción de un autor de fama mundial a un traductor con mucha experiencia. De los 20 libros que encontré de Peter Handke en el catálogo de la Biblioteca Nacional de Madrid, si no me engaño, sólo 7 han sido traducidos por un único traductor (Eustaquio Barjau), los restantes 13 cada uno por un traductor diferente, mientras que en las fichas de este catálogo con las obras de Thomas Bernhard siempre aparece el mismo apellido de traductor: Miguel Sáenz. Me pregunto porque la obra de Handke se ha traducido por 14 traductores? ¿Por razones económicas? ¿Por traductológicas?

En la cubierta de la novela de Handke está escrito: «Manchmal die Vorstellung, ein Schrifsteller hätte vor allem die eine Pflicht: eine Landschaft zu verewigen» $[=$ «De vez en cuando la idea, que el escritor tiene una obligación: eternizar una región»]. Esta frase debería haber sido una señal de aviso: «Cuidado! regionalismos!»

En la traducción española podemos encontrar algunas transformaciones que analizaremos sobre su carácter de ser obligatorias, involuntarias o deliberadas. Obligatorias son las transformaciones de palabras alemanas compuestas que se reproducen en español por grupos sintagmáticos. Ejemplos:

Endstationschleife: el recodo de la estación final.

Torfbauernhütten: cabañas de camponeses turberos.

Sobre las otras categorías es difícil decir algo concreto sin tener la posibilidad de preguntar al traductor. La traductora de la novela de Handke, parece, no conocía austriacismos. Por eso una frase como «Aquí, en el musgo [...] una montaña se yergue justamente delante de la otra» (p. 17), debe ser, para un castellano-hablante, totalmente incomprensible (y me pregunto por qué no lo era ya para el traductor

\footnotetext{
*Dirección del autor: Fachbereich Romanistik, Akademiestrasse 24, A-5020 Salzburg, Austria. Correo electrónico: Dieter.Messner@sbg.ac.at
} 
y el lector de la editorial española). La palabra «Moos» que tiene el significado de 'pantano' en los dialectos alemanes del sur («Moor» en el acrolecto alemán) es una forma homógrafa del lexema alto-alemán «Moos», que significa 'musgo').

El segundo aspecto, la reproducción literaria del lenguaje oral, lo ilustro con la autora austríaca de libros infantiles Christine Nöstlinger que emplea formas dialectales en los diálogos de los protagonistas de sus novelas. Ella es bien conocida también en España con 200 fichas en el catálogo de la Biblioteca Nacional en Madrid. Un ejemplo: Der geheime Großvater, publicado en 1986 (Viena: Jugend und Volk) y traducido al español en 1990 bajo el título El abuelo misterioso (Madrid: Espasa-Calpe. Traductor Luis Pastor). Allí leemos la frase: «Net einmal mehr eine Germ habens,» lo que significa literalmente ' $\mathrm{Ni}$ siquiera tienen una porción de levadura'. En la traducción española la frase es: «Ni siquiera una misera galleta» lo que no corresponde al original. Y la variedad diatópica «net» del alto - alemán «nicht» ('no') no se reproduce.

Ya a partir del título encontramos no sólo errores de traducción ('el lado secreto del abuelo' y no 'misterioso' como consta en el original) sino también un gran desconocimiento de lexemas sólo usados en Austria. Ejemplos:

Und jetzt fliegt die Schürze durch die Luft! Auf dem Küchenstockerl landet sie.

Ahora el delantal vuela por el aire. Aterriza en un gancho de la cocina.

«Stockerl» no está en los diccionarios bilingües alemán - español; significa 'taburete', con el sufijo diminutivo «-erl» típico del sur de Alemania y de Austria.

Das Bauchweh [...] komme sicher davon, daß der Großvater warmen Germteig gegessen habe.

[...] el dolor de barriga era porque el abuelo había comido muchas moras verdes.

Pero «Germteig» es 'masa de levadura'.

Buchteln gibt's keine heut.

Hoy yá no quedan bizcochos .

Pero «Buchteln» son 'rollos rellenos de mermelada'.

En este ejemplo hay más dos fenómenos no traducidos: primero: «no quedar» es 'sobrar'. Pero el texto alemán significa: «no preparamos los rollos para hoy». Segundo: el aspecto oral en el adverbio de tiempo «heut» que pierde en el alemán del sur su «e» final de «heute».

[ ..] zusammen mit einem Biskottenfisch und einem vierblättrigen Kleeblatt.

[...] con un bizcocho de pescado y un trébol de cuatro hojas.

Entre los talismanes que se regalan en Austria en la noche de fin de año hay también un bizcocho, en forma de pez, y que no tiene nada de ver con el pescado.

[...] er hatte einen grünen Hubertusmantel an.

[...] llevaba un abrigo de color verde.

Un «Hubertusmantel» no es nada más que un 'loden', una prenda de vestir típica de la gente del campo en los siglos pasados, y después de los cazadores que tienen como patrón al Santo Huberto. 
Es interesante notar que el traductor de esta novela ha traducido también otras novelas de Christine Nöstlinger y no le parecía necesario documentarse con los diccionarios específicos del dialecto vienés. También aquí una observación: he contado en el catálogo de la Biblioteca Nacional 11 traductores diferentes para las 15 obras de Nöstlinger.

Parece que el desconocimiento de como se habla en Austria es una constante en las traducciones de las novelas de Christine Nöstlinger al español. También en otro de sus libros hallamos errores bastante graves: Anatol und die Wurschtelfrau (WienMünchen: Jugend und Volk 1983) = Anatol y Desiree. (Madrid: Espasa-Calpe 1987. Traductora Carmen Seco). Ejemplos:

Verkalkte Urschel, sagte der Großvater.

Urschel, esclerótica!, dijo el abuelo.

El origen de la palabra popular «Urschel» con el significado de 'tonta' es el nombre propio feminino «Ursula.» Es un fenómeno muy común de la Alemania meridional insultar a una persona con la forma abreviada de un nombre: también hay «Trudscherl» ['poco hábil'] que viene de «Trude,» o para hombres «Tadedl,» ['estúpido'] de «Thaddäus», y para hombres groseros «Rüpel,» ['maleducado'] que viene de «Rupert» Llamo la atención a estas denominaciones depreciativas porque tienen todas un sufijo diminutivo.

Sería fácil enumerar muchas otras traducciones no correctas de palabras austríacas, como «Blunzen,» que es 'morcilla,' y no «albóndigas»; «Aschanti,» que son 'cacahuetes' (según una tribu africana) y no «bizcochos,» como «Kipferl» que es un 'cuernecito', 'cruasán' y no «miga», etc., etc.

Leyendo estas traducciones españolas de textos con rasgos austríacos me pregunté por qué había errores tan grandes. Acredito haber encontrado la solución: en ningún diccionario bilingüe aleman - español, incluso en aquellos de gran tamaño, aparecen estos austriacismos “ 'Moos»y «Germ». Algunos, no todos se registran en diccionarios alemanes monolingües de cierto volumen (por ejemplo en el Duden Universalwörterbuch, de más de 2.000 páginas, München /Zürich/Viena: Duden 1989, 2a . ed.) o en diccionarios de austriacismos (Jakob Ebner, Duden - Wie sagt man in Österreich? Wörterbuch der österreichischen Besonderheiten. Mannheim / Wien [etc.]: Bibliogr. Institut, Dudenverlag, 1969), de que, parece, los traductores no disponían cuando traducían estas novelas.

Para concluír este capítulo consta destacar que ninguno de los traductores españoles ha intentado sustituír los austriacismos por regionalismos españoles, es decir, transponer la acción de las novelas austríacas a un ambiente español.

Es una especie de tópico en las investigaciones traductológicas la de llamar la atención sobre el receptor de un texto traducido. Por eso tenemos que preguntarnos quiénes son los posibles receptores españoles de una novela de Peter Handke o de Christine Nöstlinger. Sería interesante analizar la recepción de estos libros entre el público español. Es la tarea de un ramo de la filología, la sociología literaria, la de investigar porque uno compra un nuevo libro. En un nivel algo diferen- 
te ya se ha analizado la recepción investigándose por ejemplo cuantos succesores tiene la novela El nombre de la rosa de Umberto Eco, o cómo ha impresionado el pesimismo crítico de Thomas Bernhard a los intelectuales europeos que ahora identifican la Austria literaria de Bernhard con la realidad, mientras que los filólogos descubren que lo que escribió Bernhard era un discurso literario y no autobiográfico. Pero no se ha investigado quien compra los libros infantiles de Christine Nöstlinger y qué le parece la traducción.

Creo que hablar de un receptor abstracto y único, aquí de un lector de textos literarios, no es adecuado a la situación comunicativa. Si falta un análisis exacto tenemos que recurrir a otro procedimiento. Sobre Peter Handke dicen en las cubiertas de sus traducciones españolas: «Es uno de los autores en lengua alemana más conocidos [...]»; «En 1973 ganó el Premio Georg Büchner»; «Peter Handke es ejemplo, resumen y máximo exponente de los rasgos más característicos y mejores de la actual literatura en lengua alemana». Las tres citas quieren llamar la atención de posibles compradores, es decir, de lectores españoles por dos vías:

la primera: «autor muy conocido», o "máximo exponente de la literatura alemana» la segunda: «ganador de un premio» cualquier que sea (¿quién conoce en España al poeta alemán Georg Büchner excepto los germanistas?)

En ningún caso se habla de la calidad literaria o se alega a la descripción minuciosa de una pequeña región de Austria, y parece que no tiene importancia porque en la traducción de hechos típicos, por ejemplo de topónimos no se ha aspirado a la exactitud.

Una montaña llamada «Gaisberg,» topónimo y por eso intraducible, que significa la 'montaña de las cabras', es traducida por «Monte Gais,» el peñón «Urstein», es traducido por «roca primitiva,» etc. etc. Por eso no nos admiramos que tampoco haya traducciones exactas de otros términos. Un ejemplo: en la traducción española se lee: «[...] había bastante sitio en el autobús nocturno - llamado el 'trapero' - [...]». El original es: «[...] im Nachtbus - 'Lumpensammler' genannt - war viel Platz».

Pero el lexema alemán es interpretado en la traducción española como 'él que recoge trapos'. La palabra alemana marcada 'familiar' en el diccionario de austriacismos significa el último tren o autobús, que recoge a personas a las que se llama, por no haber vuelto a casa antes, «Lumpen» ['personas desordenadas']. La primera parte del compuesto es el plural del sustantivo «Lump», es decir 'sinvergüenza', y no de «Lumpen», 'trapos'.

Con este ejemplo vemos que hay varios mensajes en el acto comunicativo de traducciones literarias. Y no sé, infelizmente, cuál fue la reacción de la crítica literaria en España, es decir como recibieron estos textos.

A la autora austríaca, Elfriede Jelinek, se le ha elogiado en una campaña de publicidad tampoco por sus calidades literarias y estilísticas etc., sino, por ejemplo en el caso del libro Die Klavierspielerin (La pianista, Barcelona: Mondadori 1993. Traductor Pablo Diener Ojeda) como a la primera mujer que escribe textos eróticos como lo ha hecho yá el autor francés de Sade. ¿Podemos deducir de esta publicidad 
que al posible lector español sólo le interesa el sexo y no el texto, es decir más el mensaje que el medio?

No vale la pena reproducir todo lo que se ha escrito en textos publicitarios sobre Christine Nöstlinger; son los mismos argumentos que hemos visto antes en Peter Handke: «autora muy conocida por sus libros infantiles»; «medalla Andersen y otros premios.»

Todo eso indica también que el ambiente vienés (caracterizado por formas regiolectales del original y que la hizo famosa a Nöstlinger en los territorios de habla alemana) no tenía ninguna importancia en España.

Repito: lo que nosotros, filólogos, criticamos en una traducción llamándola mala, no tiene importancia para la editorial, ni para el público. La obra de García Lorca ha sido traducida al alemán hace 50 años, y bastante temprano se constató que algunos textos eran mal traducidos. Pero el traductor tenía un contracto exclusivo de los derechos y sólo 50 años pasados se ha permitido hacer una nueva traducción.

Podemos presuponer que las mismas condiciones antes mencionadas existen si analizamos la recepción de una novela española y su traducción alemana. Se trata de El amante bilingüe, de Juan Marsé, publicado por primera vez en 1990 (Barcelona: Planeta), y que cuenta ya con varias reediciones y una película basada en ella. La traducción alemana fue publicada, primero en hard-cover en 1990, y en 1995 en libro de bolsillo (Juan Marsé, Der zweisprachige Liebhaber, Bühl-Moos: Elster-Verlag 1990; Düsseldorf: ECON 1995. Traductor Hans-Joachim Hartstein).

En el prospecto se elogia al autor como «observador sin piedad de la sociedad española»; «ganador de dos premios, el de la Biblioteca Breve y del Ateneo de Sevilla.» La acción de la novela tiene lugar en Barcelona, en los años 70 y 80. Juan Marés y Norma Valentì, su mujer de 14 años más joven, forman un matrimonio durante pocos años. Cuando un día él vuelve a casa sorprende a su mujer en las manos de un charnego. Norma sale de la casa sin regresar jamás. Algunos años más tarde Juan se viste de charnego y se comporta así, también en la pronunciación para conseguir de su ex-mujer una noche de amor. Los personajes del texto hablan castellano, algunos catalán, y se imita también el habla de los charnegos de Barcelona: por eso he escogido esta novela. Añado también la traducción francesa: L'Amant bilingue, traduit de l'espagnol par JeanMarie Saint-Lu (Paris: Christian Bourgeois Editeur 1996).

Mientras que la lengua castellana siempre es traducida al alemán sin restricciones el traductor alemán tomó varias soluciones para reproducir los trozos catalanes del original.

Primero: no ha traducido el original, o sólo una parte. Ejemplos:

Posi's en contacte amb Aserluz, i li faran [...]

Tr.al. Posi's en contacte amb Aserluz, i li faran [...]

Tr.fr. Posi's en contacte amb Aserluz, i li faran [...] [nota: contactez Aserluz et ils vous feront] Assessorament lingüistic. Digui? .

Tr.al. Assessorament lingüistic. Digui?

Tr.fr. Assessorament lingüistic. Digui? [nota: Bureau linguistique. J'écoute] 
Segundo: tradujo el texto catalán añadiendo el sintagma preposicional «auf Katalanisch» (= «en catalán»). Ejemplos:

[...] un viandante [...] le dijo: Escolti, perdoni, De què se'n fot vostè?

Tr.al. [...] ein Mann sagte auf Katalanisch: escolti, perdoni. Worüber machen Sie sich lustig. Tr.fr. [...] un passant [...] lui dit: «Escolti, perdoni. De què s'en fot, vostè? [nota: Dites, excusez - moi. Vous vous foutez de qui?]

Ja. No es coneix ni ella mateixa, gruño Valls Verdú [...] .

Tr.al. Jaja, sie kennt sich selber nicht, brummte Valls Verdú auf Katalanisch [...]

Tr.fr. Ja. No es coneix ni ella mateixa. [nota: Ouais. Elle ne se connaît même pas elle même].

I ara, anem- s'en, tu, añadió dirigiendo se a Norma [... ]

Tr.al. Zu Norma gewandt fügte er auf Katalanisch hinzu: Und jetzt laß uns gehen [...]

Tr.fr. I ara anem-s'en, tu, ajouta-t-il en s'adressant à Norma [nota: Et maintenant, on s' en va ... ]

Tercero: tradujo las palabras catalanas sin otra indicación: Ejemplo:

Llepaculs, filiprim [...] Torracollons

Tr.al. Arschkriecher, Schleimer, [...] Wichser

Tr.fr. Llepaculs i filiprim; [...] Torracollons [ nota: Lèche-cul constipé [...] Casse-couilles]

En todos los ejemplos vemos que las palabras catalanas se traducen por palabras del acrolecto alemán. Alusiones al ambiente de Barcelona se hacen expressis verbis.

Nos queda analizar ahora cómo ha reproducido el traductor alemán de la novela española el registro sociolectal de los llamados charnegos porque ya antes nos hemos preguntado por qué las formas regiolectales austríacas no han sido respectadas en las traducciones españolas. En el texto original este término "charnego» aparece varias veces, en algunos casos mismo definido así:

[...] no tardé en descubrir que su debilidad [la de Norma] eran los murcianos de piel oscura y sólida dentadura. Charnegos de todas clases. Taxistas, camareros, cantaores y tocaores de uñas largas y ojos felinos. Murcianos que huelen a sobaco, a sudor, a calcetín sucio.

Tr.al. [...] bald entdeckte ich, daß sie eine Schwäche für Murcianer mit dunkler Haut und kräftigem Gebiß besaß. Charnegos aller Arten. Taxifahrer, Kellner, Flamencosänger und Flamencogitarristen mit langen Fingernägeln und Katzenaugen. Murcianer, die unter den Achseln riechen, nach Schweiß, nach schmutzigen Socken [...]

Pero no sólo de manera directa se alude al inmigrante sur-español que busca trabajo en Barcelona, también se le caracteriza por el empleo de un registro lingüístico específico. Ejemplo: 
Porque uzté e mu güeno.

Son cuatro los fenómenos en esta frase que indican la procedencia geográfica y social : el ceceo, la pérdida de la «S» final y del diptongo «uy» como también el cambio de la oclusiva inicial «b» para «g». Esta forma lingüística estilizada por el autor requiere, en la traducción, un análisis más profundo. Si comparamos las formas del tratamiento, es decir el «Usted» castellano, y el «vostè» catalán, constatamos que les corresponde en la traducción siempre la forma alto-alemama «Sie,» mientras que se reproduce la forma acharnegada «uzté» con la forma alemana monoptongada «Se,» oriunda del Norte: ejemplo:

Uzté déjeme a mí, zeñora, que zoy un artista.

Tr.al. Lassen Se mich nur machen, Señora, ich bin 'n Künstler.

Tr.fr. Laissez-moi faire, sère Madame, ze suis un artiste.

La misma frase en los dialectos alemanes del sur (Baviera, Austria) sería:

Loss'n $\underline{S}^{‘}$ mi nua moch'n: i bin a Künstla.

Si se propone a alemanes esta versión meridional se ríen de ella: uno de los presidentes de Alemania era bávaro, y cuando hablaba en público su pronunciación era objeto de bromas. Antes, en los últimos 60 años los alemanes identificaban al presidente lingüísticamente siempre con una variante del norte. Nosotros, los filólogos analizamos también las conotaciones de regiolectos, algunos de ellos aceptables por mucha gente, otros repudiados. Si el traductor alemán de la novela española hubiera escogido la variante bávara no lo habría aceptado ningún crítico o editor.

Lo que constatamos en el último ejemplo del texto de Juan Marsé es que el autor repite tres veces el conocido fenómeno del ceceo considerado como típico del sur de España. El traductor, claro, no puede encontrar en alemán ninguna correspondencia: lo que hace es indicar un registro diastrático sólo con un único rasgo, con la forma del pronombre personal «Se,» pero que neutraliza en el mismo instante porque no traduce la palabra española «Señora.» Otro ejemplo:

Porque uzté e mu güeno.

Tr.al. Weil $\underline{\mathrm{Se}}$ 'n guter Mensch sind.

Uno tiene que preguntarse si realmente era necesario reproducir los rasgos primitivamente diatópicos murcianos y después, en Barcelona, diastráticos (nivel social bajo) por rasgos dialectales del alemán del norte. Por lo demás, el traductor no fue siempre consecuente, mezclando «Sie» y «Se». Ejemplo:

E uzté muy zalerosa.

Tr.al. Sie haben Hummeln im Hintern.

El traductor intentó caracterizar también la variante española meridional por un comentario:

Zí, zeñó.

Tr.al. Ja, Señor, lispelte er. [ = 'ceceaba']. 
Pero el traductor no sólo inserta formas fonéticas dialectales sino también emplea un vocabulario de procedencia septentrional para caracterizar el lenguaje que emplean los charnegos de Barcelona. Ejemplos:

No pero si es una cosita de na.

Tr.al. Nee, das iss doch nur'n Klacks.

Tr.fr. Mais, c'est que c'est un petit truc de rien de tout.

[...] de la Crida me la tienen jurada.

Tr.al. [...] jemanden auf'm Kieker haben.

Tr.fr. [...] ces types de la Crida [...] ils veulent me flanquer la trouille.

E estoy mu malamente de dinero.

Tr.al. Ich bin schwer in'n Miesen.

Tr.fr. et ça va très mal côté arzent.

Ahora vendo persianas.

Tr.al. Ich verbimmel jetzt Jalousien.

Tr.fr. Maintenant je vends des stores vénitiens.

He hecho, con mis estudiantes, un experimento: son 25 personas, austríacas, que hablan la variante bávara del alemán. Estas no han podido descubrir el significado de las cuatro palabras antes subrayadas, porque provienen (lo indica un gran diccionario monolingüe alemán) del Norte, del medio-bajo-alemán, es decir de la variante regional hablada alrededor de Hamburgo.

No sólo tenemos que descubrir el significado de unos sustantivos en la traducción, si no también un adverbio. Ejemplo:

No se haga uzté mala zangre.

Tr.al. Nehmen Se's ma nich so tragisch.

Tr.fr. Ne vous faites pas de mauvais sang.

Este «ma» procede del norte-alemán y tiene el significado 'sólo', y es por completo incomprensible a la gente del sur que lo interpreta como pronombre personal, «mir» ['a mí'] del alemán estándar, en dialecto «ma».

Si la tarea del traductor es la de verbalizar la intención del autor en una nueva lengua diferente de la original, en nuestro caso la de los inmigrantes en Barcelona, el que tradujo el texto claramente ha fallado: no ha conseguido crear consecuentemente un ámbito cultural específico, el de los charnegos en Barcelona, porque contraponía a la descripción socio-lingüística («zoy anarfabeto») un medio lingüístico procedente del alemán del Norte, que en gran parte no se comprende en el Sur. La alusión a «tocaores» de flamenco, en el original debe ser, para otro tipo de lector, el instruído, un choque si estas personas hablan un alemán dialectal. 
No quiero terminar aquí. Quiero mencionar también la traducción francesa de la novela de Juan Marsé L'Amant bilingue. El traductor francés no ha escogido el mismo procedimiento como el traductor alemán. Para el texto escrito en castellano emplea el francés estándar. Las frases y palabras catalanas las reproduce en catalán añadiendo cada vez una nota a pie de página. Lo que interrompe bastante la lectura y transforma la novela en otro texto.

Para la lengua acharnegada ha tomado unas formas francesas extrañas, hace cecear a las personas en francés.

Laissez-moi faire, sère Madame, ze suis un artiste.

He preguntado también a franceses cultos por su opinión sobre la manera de escribir. Con la excepción de una persona que creía ver en estas palabras la pronunciación de africanos, las demás no relacionaban el cambio fonético de las sibilantes con un registro socio- o regiodialectal francés sino con una deformación anatómica en la boca. Y eso significa que también la traducción francesa no refleja la intención del autor español, elaborada, hay que decirlo, para lectores españoles. Es absurdo que en el texto francés a la invitación de parler en catalan «Parli catalan si us plau», la respuesta es «Ze le parle très mal, Madame».

Mejor me parece la solución que ha tomado Miguel Sáenz en la traducción de la novela alemana de Alfred Döblin: Berlin. Alexanderplatz (München: dtv 1965. Barcelona: Destino 1996). En la traducción de la pronunciación berlinense no busca un registro español parecido, pero deja en el nombre del protagonista el sufijo afectivo alemán, es decir no transpone el lugar alemán a un lugar español.

Herr Matter an den Apparat, hast du nicht vorher die Oogen geplinkt, Reinhold, Jungeken [...] Da kommt Karlchen schon wieder, och Karelein, Karelein [...] haste Wehwehchen, nee, ick muß rasen nach Berlin, du bleibst doch, Mieze, ick muß, man kann

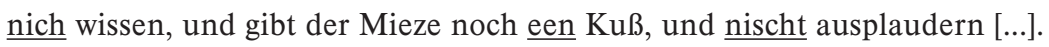

Sr. Matter, al teléfono, no has guiñado un ojo antes, Reinhold, chico [...]. Y ahí vuelve ya Karlchen, ay Karelein, hermoso [...] te has hecho pupa, no, tengo que volver a toda prisa a Berlín, tú quédate, Mieze, yo me tengo que ir, nunca se sabe, y le da a Mieze un beso y no lo cuentes por ahí, [...].

Llego al final de mi análisis. Hemos visto que al lado de evidentes errores provenientes de un desconocimiento de la lengua del texto original hay otro aspecto, mucho más importante: la ausencia de una decisión a tomar por el traductor antes de empezar: la decisión entre una traducción documental que hace del lector un observador para acercarle un mundo extraño que no es el suyo, o una traducción instrumental en la que el lector participa, como si fuera el entorno propio.

Tanto en la novela austríaca de Peter Handke como en aquella de Juan Marsé se describe un lugar concreto e identificable: la ciudad de Salzburgo y la ciudad de Barcelona, y por eso las he escogido, son textos fáciles sin gran pretensión estilística. 
Eso significa que ya no hay una opción de escoger entre las dos maneras de traducción, documental o instrumental: sólo es posible la documental. Por no haberlo hecho los traductores de las novelas mencionadas se ha perdido la homogeneidad de los textos. La calle más importante de Salzburgo no puede traducirse en "calle Getreide,» como tam poco pueden verterse las pronunciaciones de los andaluces de Barcelona en un sociolecto de Hamburgo.

\section{Resumen \\ SOBRE TRADUCCIONES FRACASADAS}

Se analizan las traducciones de textos literarios (alemán-español) de Peter Handke (El chino del dolor) y Christine Nöstlinger (El abuelo misterioso; Anatol y Desiree) y (español-alemán) de Juan Marsé (El amante bilingüe) con relación a las expresiones regionales y sociolectales que los autores emplean para caracterizar tanto paisajes como personas. Las traducciones españolas de los autores austríacos muestran que los traductores sólo se han servido de diccionarios bilingües generales que no contienen las expresiones típicas del alemán austríaco. Por eso algunas palabras españolas no tienen el mismo significado que las alemanas. Pero parece que eso no importa al lector español. Para la traducción al alemán de las expresiones charnegas de la novela de Juan Marsé el traductor escoge palabras del alemán hablado en las regiones septentrionales, lo que impide que puedan llegar a entenderlas los alemanes del sur.

\section{Povzetek \\ O NEUSPELIH PREVODIH}

V članku so obravnavani prevodi književnih besedil Petra Handkeja (Der Chinese des Schmerzes) in Christine Nöstlinger (Der geheime Großvater/El abuelo misterioso in Anatol und die Wurschtelfrau/Anatol y Desiree) iz nemščine v španččino ter Juana Marséja (El amante bilingüe) iz španščine v nemščino. Analizirani so pokrajinski in sociolektalni izrazi, ki jih avtorji uporabljajo za označevanje pokrajin in oseb. Španski prevodi avstrijskih avtorjev kažejo, da so prevajalci pri delu uporabljali zgolj splošne dvojezične slovarje, ki ne vsebujejo za avstrijsko nemščino značilnih izrazov. Zato se španski prevodi pomensko mestoma oddaljijo od izvirnikov. Toda kot kaže, to španskih bralcev ne moti. Kar pa zadeva nemški prevod romana Juana Marséja, prevajalec za izraze, ki so tipični za priseljence, izbere ustreznice iz pogovorne nemščine, kot se uporablja na severu, zaradi česar imajo težave z razumevanjem govorci južnih nemških različic. 